Supporting Information for

\title{
Synthesis, characterization, in vitro antitumor activity of ruthenium(II) polypyridyl complexes tethering EGFR-inhibiting 4-anilinoquinazolines
}

Jun Du, ${ }^{a}$ Yan Kang, ${ }^{\text {a, b }}$ Yao Zhao, ${ }^{\text {, }}$ Wei Zheng, ${ }^{\mathrm{b}}$ Yang Zhang, ${ }^{\mathrm{b}}$ Yu Lin, ${ }^{\mathrm{b}}$ Zhaoying Wang, ${ }^{\mathrm{b}}$ Yuanyuan Wang, ${ }^{\mathrm{b}}$ Qun Luo, ${ }^{\mathrm{b}}$ Kui Wu, ${ }^{\mathrm{b}}$ Fuyi Wang ${ }^{\mathrm{b}}$

${ }^{a}$ College of Chemistry and Materials Science, Key Laboratory of Functional Molecular Solids, the Ministry of Education, Anhui Laboratory of Molecular-Based Materials, Anhui Normal University, Wuhu 241000, P. R. China.

${ }^{b}$ Beijing National Laboratory for Molecular Sciences; CAS Key Laboratory of Analytical Chemistry for Living Biosystems; Beijing Centre for Mass Spectrometry; Institute of Chemistry, Chinese Academy of Sciences, Beijing 100190, P. R. China. Email: yaozhao@iccas.ac.cn; fuyi.wang@iccas.ac.cn. 
Table S1. Crystallographic data for compound K5

\begin{tabular}{|c|c|}
\hline Formula & $\mathrm{C} 66 \mathrm{H} 70 \mathrm{Cl} 2 \mathrm{~F} 14 \mathrm{~N} 14 \mathrm{O} 8 \mathrm{P} 2 \mathrm{Ru}$ \\
\hline Molecular weight & 1687.27 \\
\hline Crystal system & Triclinic \\
\hline Space group & $P-1$ \\
\hline$a(\AA)$ & $10.7727(14)$ \\
\hline$b(\AA)$ & $15.957(2)$ \\
\hline$c(\AA)$ & $22.198(3)$ \\
\hline$\alpha\left(^{\circ}\right)$ & $104.432(2)$ \\
\hline$\beta\left({ }^{\circ}\right)$ & $103.301(2)$ \\
\hline$\gamma\left({ }^{\circ}\right)$ & $93.023(2)$ \\
\hline$V\left(\AA^{3}\right)$ & $3571.7(8)$ \\
\hline $\mathrm{Z}$ & 2 \\
\hline Crystal size $(\mathrm{mm})$ & $0.21 \times 0.17 \times 0.04$ \\
\hline Crystal description & plate \\
\hline Crystal color & red \\
\hline$D_{\mathrm{x}}\left(\mathrm{mg} / \mathrm{m}^{3}\right)$ & 1.569 \\
\hline$\mu\left(\mathrm{mm}^{-1}\right)$ & 0.441 \\
\hline$T(\mathrm{~K})$ & 173.15 \\
\hline Wavelength $(\AA)$ & 0.71073 \\
\hline$\theta$ range for data collection & 1.327 to $27.483^{\circ}$ \\
\hline Data collection mode & $\omega$ scan \\
\hline Index ranges & $-13 \leq \mathrm{h} \leq 13,-20 \leq \mathrm{k} \leq 20,-28 \leq 1 \leq 28$ \\
\hline Reflections collected & 32242 \\
\hline Independent reflections & $16240[\mathrm{R}(\mathrm{int})=0.0501]$ \\
\hline Data / restraints / parameters & $16240 / 0 / 993$ \\
\hline Largest diff. peak and hole (e $\AA^{-3}$ ) & 0.870 and -0.861 \\
\hline
\end{tabular}


Table S2. Selected bond lengths $(\AA)$, angles and torsion $\left(^{\circ}\right)$ for compound $\mathbf{K 5}$

\begin{tabular}{cccc}
\hline $\mathrm{Ru}(1)-\mathrm{N}(1)$ & $2.058(3)$ & $\mathrm{Ru}(1)-\mathrm{N}(3)$ & $2.044(3)$ \\
$\mathrm{Ru}(1)-\mathrm{N}(2)$ & $2.061(3)$ & $\mathrm{Ru}(1)-\mathrm{N}(4)$ & $2.061(3)$ \\
$\mathrm{Ru}(1)-\mathrm{N}(5)$ & $2.088(3)$ & $\mathrm{Ru}(1)-\mathrm{N}(10)$ & $2.095(3)$ \\
$\mathrm{N}(1)-\mathrm{Ru}(1)-\mathrm{N}(2)$ & $79.33(13)$ & $\mathrm{N}(5)-\mathrm{Ru}(1)-\mathrm{N}(10)$ & $89.90(12)$ \\
$\mathrm{N}(3)-\mathrm{Ru}(1)-\mathrm{N}(4)$ & $79.23(14)$ & & \\
\hline
\end{tabular}




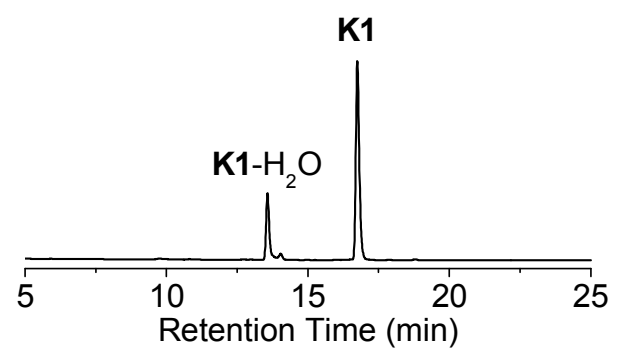

b

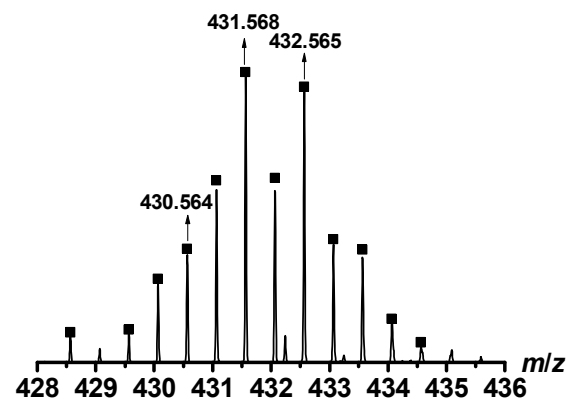

c

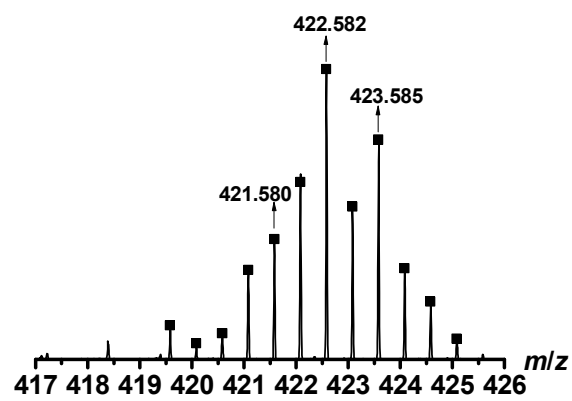

Figure S1. (a) HPLC chromatogram with UV detection at $254 \mathrm{~nm}$ for compound $\mathbf{K 1}(10 \mu \mathrm{M})$ in PBS after incubation at $310 \mathrm{~K}$ for $1 \mathrm{~h}$. Mass spectra for HPLC fractions: (b) $\left[\mathbf{K} \mathbf{1}-\mathbf{H}_{\mathbf{2}} \mathbf{O}-\mathrm{PF}_{6}\right]^{2+}$, $m / z$ theoretical: 422.579 , found: 422.582 ; (c) $\left[\mathbf{K 1}+\mathrm{H}-\mathrm{PF}_{6}\right]^{2+}, m / z$ theoretical: 431.562 , found: 431.568. The black squares represent simulated isotopic patterns of the corresponding species. 
a

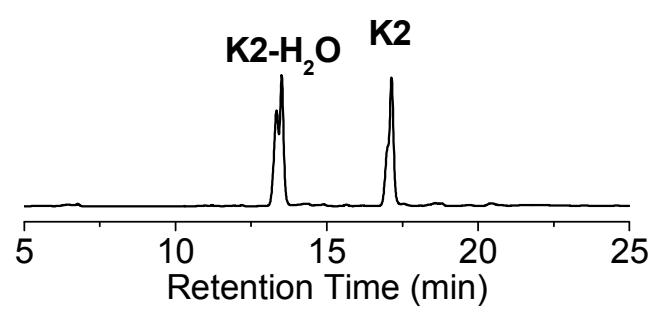

b

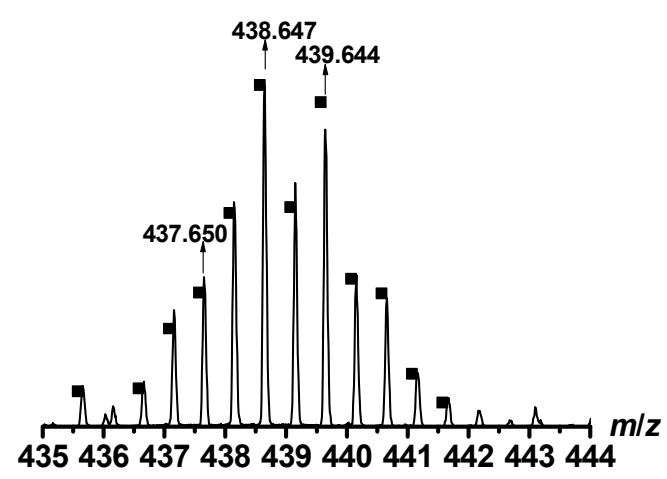

C

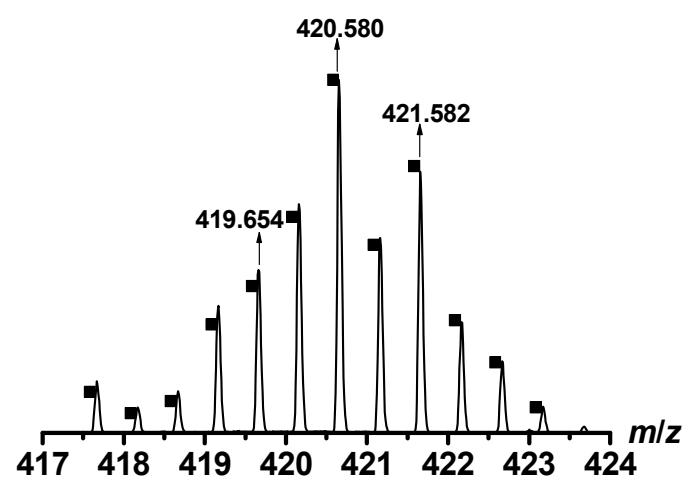

Figure S2. (a) HPLC chromatogram with UV detection at $254 \mathrm{~nm}$ for compound $\mathbf{K 2}(10 \mu \mathrm{M})$ in PBS after incubation at $310 \mathrm{~K}$ for $1 \mathrm{~h}$. Mass spectra for HPLC fractions: (b) $\left[\mathbf{K} \mathbf{2}-\mathbf{H}_{\mathbf{2}} \mathbf{O}-\mathrm{PF}_{6}\right]^{2+}$, $m / z$ theoretical: 420.582, found: 420.580; (c) $\left[\mathbf{K 2}+\mathrm{H}-\mathrm{PF}_{6}\right]^{2+}, m / z$ theoretical: 438.571, found: 438.647. The black squares represent simulated isotopic patterns of the corresponding species. 
a

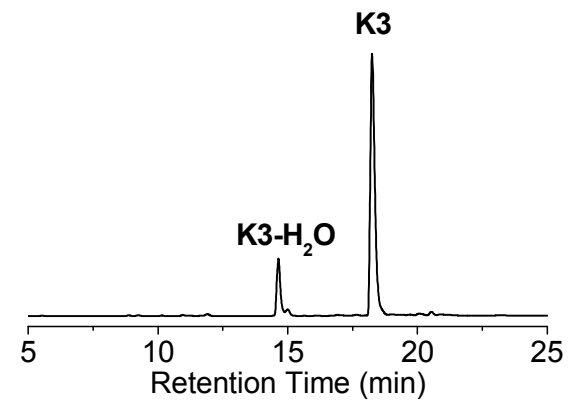

b

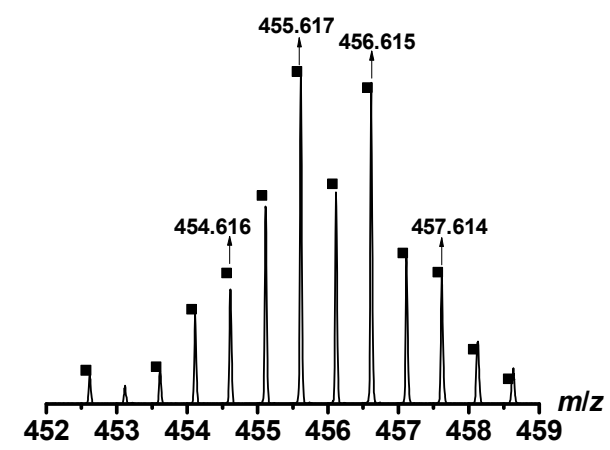

c

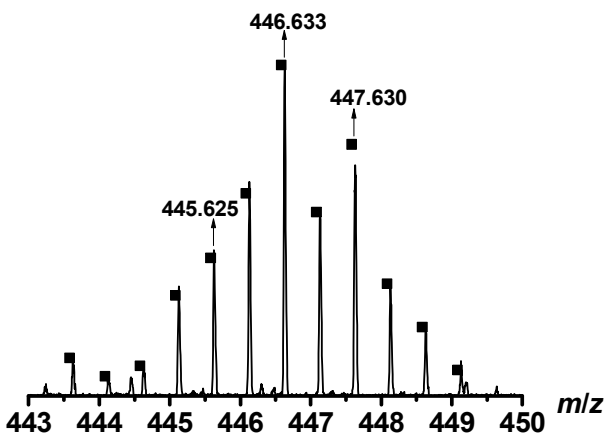

Figure S3. (a) HPLC chromatogram with UV detection at $254 \mathrm{~nm}$ for compound $\mathbf{K 3}(10 \mu \mathrm{M})$ in PBS after incubation at $310 \mathrm{~K}$ for $1 \mathrm{~h}$. Mass spectra for HPLC fractions: (b) $\left[\mathbf{K} \mathbf{3}-\mathbf{H}_{2} \mathbf{O}-\mathrm{PF}_{6}\right]^{2+}$, $m / z$ theoretical: 446.579, found: 446.633; (c) $\left[\mathbf{K 3}+\mathrm{H}-\mathrm{PF}_{6}\right]^{2+}, m / z$ theoretical: 455.562, found: 455.617. The black squares represent simulated isotopic patterns of the corresponding species. 
a

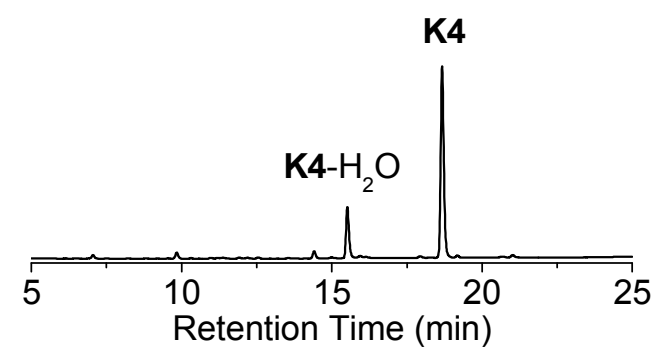

b

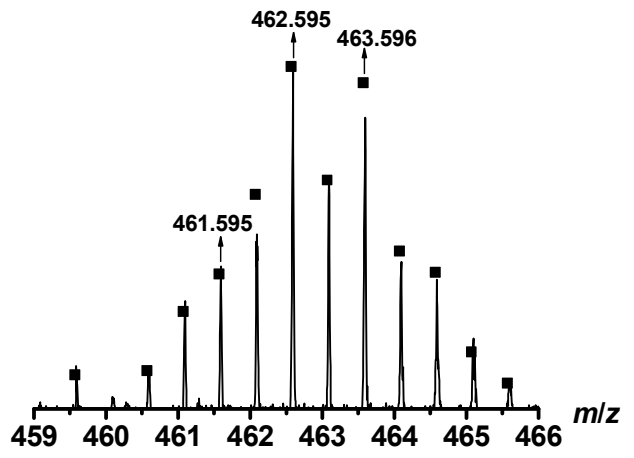

C

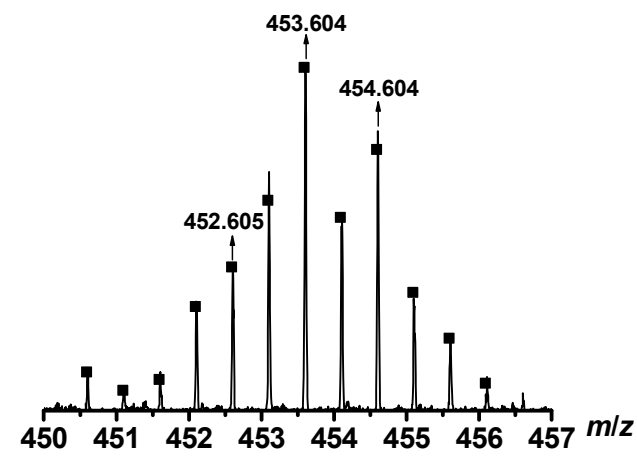

Figure S4. (a) HPLC chromatogram with UV detection at $254 \mathrm{~nm}$ for compound $\mathbf{K 4}(10 \mu \mathrm{M})$ in PBS after incubation at $310 \mathrm{~K}$ for $1 \mathrm{~h}$. Mass spectra for HPLC fractions: (b) $\left[\mathbf{K} 4-\mathbf{H}_{2} \mathbf{O}-\mathrm{PF}_{6}\right]^{2+}$, $m / z$ theoretical: 453.587, found: 453.604; (c) $\left[\mathbf{K 4}+\mathrm{H}-\mathrm{PF}_{6}\right]^{2+}, m / z$ theoretical: 462.570, found: 462.595. The black squares represent simulated isotopic patterns of the corresponding species. 


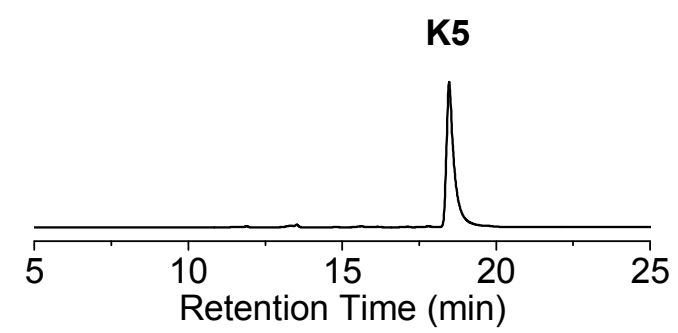

Figure S5. HPLC chromatogram with UV detection at $254 \mathrm{~nm}$ for compound $\mathbf{K 5}(10 \mu \mathrm{M})$ in PBS after incubation at $310 \mathrm{~K}$ for $1 \mathrm{~h}$. 


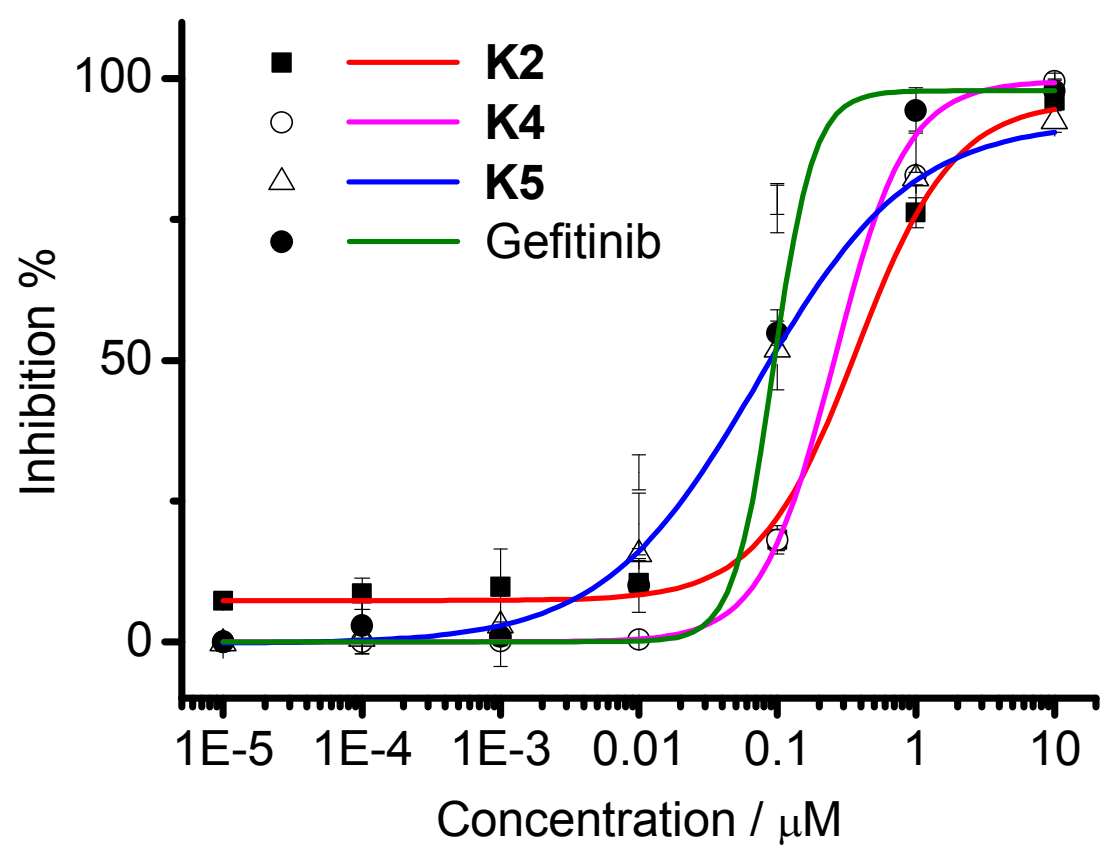

Figure S6 Dose-response inhibition curves of the ruthenium complexes K2, K4, K5 and gefitinib against EGFR. Points: mean $\pm \mathrm{SD}$ of triple determinations. 


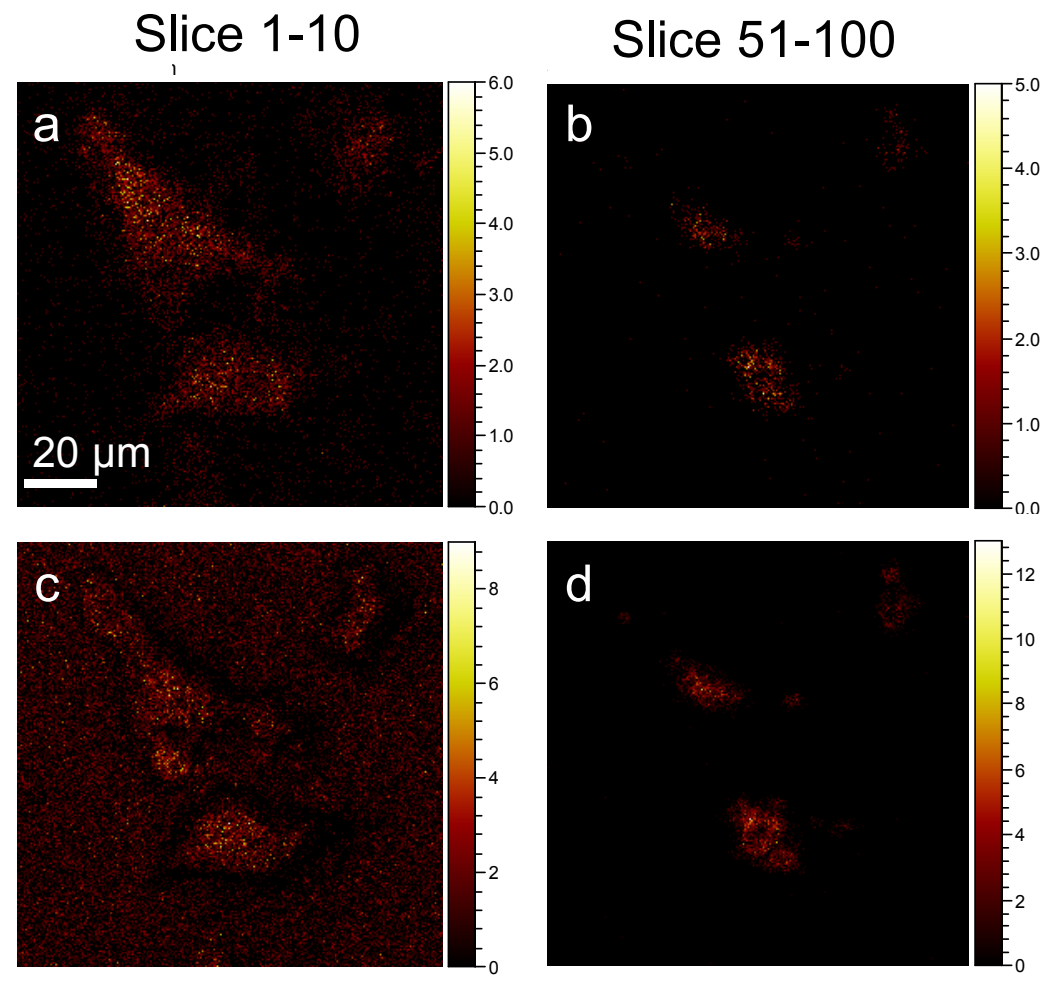

Figure S7. TOF-SIMS images obtained from HeLa cells treated with complex K2 $(50 \mu \mathrm{M})$. The first column depicts the sum of signals of the $1-10$ slices, which corresponds to the surficial level of the cells (membrane). The second column corresponds to the 51-100 slices, which depicts the deep inside of the cells (nucleus). (a) Signal of the endogenous phosphocholine fragments at $\mathrm{m} / \mathrm{z}$ 184.51 as the marker. (b) Signal of the endogenous deoxyribose fragments at $m / z 81.26$ as the marker. (c) and (d) indicates the signal of the Ru-containing fragments for K2, $m / z 412.91$ ([K2 $\left.\mathrm{L} 1-\mathrm{HCl}-\mathrm{PF}_{6}\right]^{+}, \mathrm{C}_{20} \mathrm{H}_{15} \mathrm{~N}_{4} \mathrm{O}_{2} \mathrm{Ru}$ requires 413.04) and $449.65\left(\left[\mathbf{K 2}-\mathrm{L} 1-\mathrm{PF}_{6}\right]^{+}, \mathrm{C}_{24} \mathrm{H}_{15} \mathrm{~N}_{4} \mathrm{O}_{2} \mathrm{Ru}\right.$ requires 449.01 ). The signal intensities are displayed on a colour scale, which are directly related to the level of detected ions of interest. 
Slice $1-10$
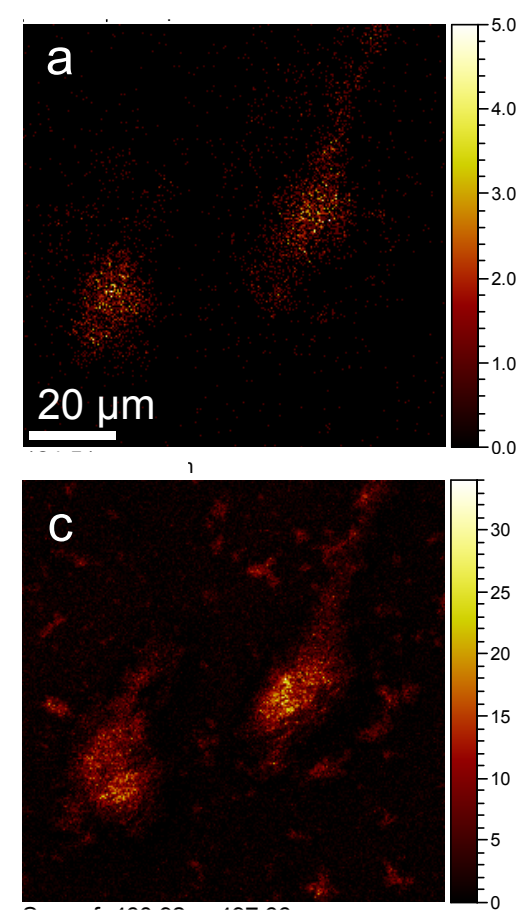

Slice $51-100$
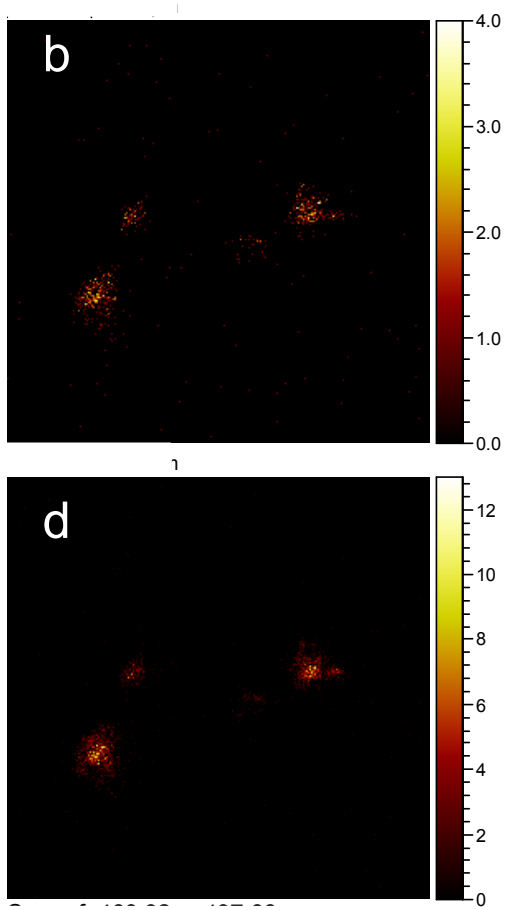

Figure S8. TOF-SIMS images obtained from HeLa cells treated with complex $\mathbf{K 3}(50 \mu \mathrm{M})$. The first column depicts the sum of signals of the $1-10$ slices, which corresponds to the surficial level of the cells (membrane). The second column corresponds to the $51-100$ slices, which depicts the deep inside of the cells (nucleus). (a) Signal of the endogenous phosphocholine fragments at $\mathrm{m} / \mathrm{z}$ 184.51 as the marker. (b) Signal of the endogenous deoxyribose fragments at $m / z 81.26$ as the marker. (c) and (d) indicates the signal of the Ru-containing fragments for K3, $m / z 460.92$ ([K3 $\left.\mathrm{L} 1-\mathrm{HCl}-\mathrm{PF}_{6}\right]^{+}, \mathrm{C}_{24} \mathrm{H}_{15} \mathrm{~N}_{4} \mathrm{O}_{2} \mathrm{Ru}$ requires 461.04) and $497.66\left(\left[\mathbf{K 3}-\mathrm{L} 1-\mathrm{PF}_{6}\right]^{+}\right.$, $\mathrm{C}_{24} \mathrm{H}_{16} \mathrm{~N}_{4} \mathrm{O}_{2} \mathrm{ClRu}$ requires 497.01. The signal intensities are displayed on a colour scale, which are directly related to the level of detected ions of interest. 


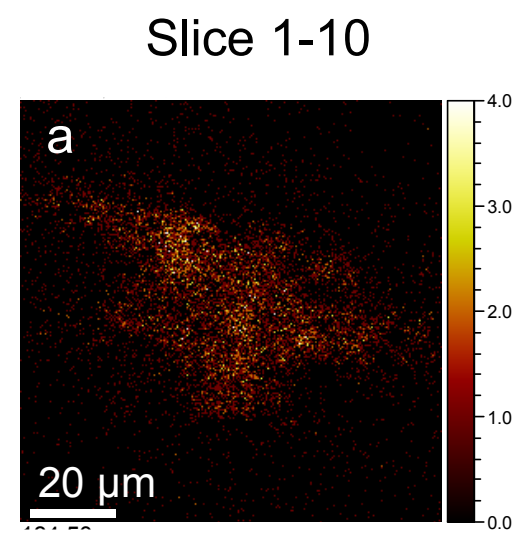

Slice $51-100$
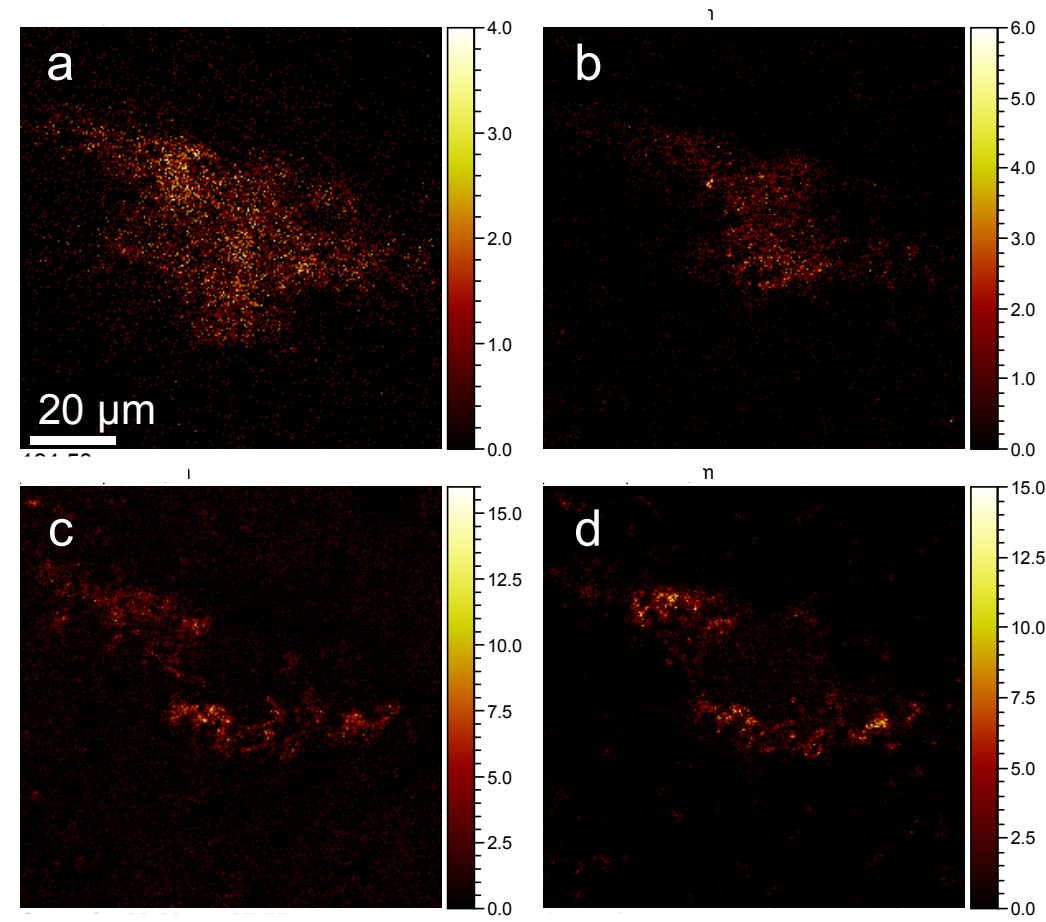

Figure S9. TOF-SIMS images obtained from HeLa cells treated with complex K4 $(50 \mu \mathrm{M})$. The first column depicts the sum of signals of the $1-10$ slices, which corresponds to the surficial level of the cells (membrane). The second column corresponds to the $51-100$ slices, which depicts the deep inside of the cells (nucleus). (a) Signal of the endogenous phosphocholine fragments at $\mathrm{m} / \mathrm{z}$ 184.51 as the marker. (b) Signal of the endogenous deoxyribose fragments at $\mathrm{m} / z 81.26$ as the marker. (c) and (d) indicates the signal of the Ru-containing fragments for K4, $m / z 460.89$ ([K4 $\left.\mathrm{L} 2-\mathrm{HCl}-\mathrm{PF}_{6}\right]^{+}, \mathrm{C}_{24} \mathrm{H}_{15} \mathrm{~N}_{4} \mathrm{O}_{2} \mathrm{Ru}$ requires 461.04) and 497.75 ([K4 - $\left.\mathrm{L} 2-\mathrm{PF}_{6}\right]^{+}$, $\mathrm{C}_{24} \mathrm{H}_{16} \mathrm{~N}_{4} \mathrm{O}_{2} \mathrm{ClRu}$ requires 497.01). The signal intensities are displayed on a colour scale, which are directly related to the level of detected ions of interest. 